\title{
Build School-Enterprise Cooperation Faculty and Develop Engineering Leading Talents
}

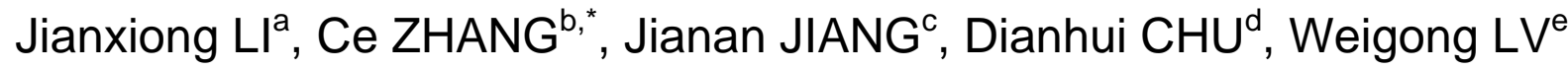 \\ School of Computer Science and Technology, Harbin Institute of Technology at Weihai, 2 \\ Cultural West Road, 264209 Weihai, Shandong Province, China \\ a13561816673@163.com, bzhangce@hitwh.edu.cn, csusan_jin@163.com, \\ dcdh@hitwh.edu.cn, ${ }^{\mathrm{e}} \mathrm{lwgswl} @$ sina.com
}

Keywords: Engineering Leading Talents, Faculty Building, School-Enterprise Cooperating Education, Talents Developing Model.

\begin{abstract}
The goal of engineering leading talent project is to train top-notch talents who are oriented towards high-end industries with practical ability, innovation and engineering leadership. With the joint training of school and enterprise as the carrier, the double-tutor system is implemented, which is an integrated implementation of multi-process and multi-participatory cross-cooperation education system and synergetic management mechanism. Based on the project goal of engineering leading talent, this paper first gives a plan of joint build of faculty between school and enterprise, which is jointly guided and flexibly administrated by school teachers and business tutors. Then, comprehensively leaded by engineering planning, practical ability and leadership, elite engineering leading talents training program will be implemented. Finally, the quality assurance mechanism of training session based on examination is given. Engineering leading talents are trained for the needs of industry high-end talents, which innovates the mode of engineering education and training, gives full play to the advantage of school-enterprise cooperation education, and provides a new channel for more school-enterprise cooperation to cultivate the leading talents needed.
\end{abstract}

\section{Introduction}

With the transformation necessity of economy and society development, the demand for high-end leading talents of industry is increasingly urgent[1-4]. Developing new engineering leading talents with top-notch practical innovation ability and engineering leadership has become an important reform content in higher institutions, especially engineering colleges[3-6]. The implementation of the engineering leading talents training program is an important measure to solve this difficult problem. It has been practiced in many schools in China[7-9], and the effectiveness has become increasingly apparent.

The training plan is jointly undertaken by school teachers and enterprise mentors[10-12]. School mainly focuses on professional courses, engineering leadership courses and basic scientific training, which is led by school teachers. Training content of enterprise is real project development and management, which is led by enterprise mentors. After having experienced a complete training in school and enterprise, the trained students have been systematically trained in specialized courses, engineering management courses, scientific research training, enterprise project development, and interaction with managers of enterprises. A variety of capacities has been upgraded. A solid foundation has been laid to become an engineering leading talent with top innovation and engineering leadership. 
It can be seen that the training plan relies on the overall advantages of school-enterprise cooperation and industry-academia co-construction, which exerts the synergistic effect of cooperating education, directly expands students' engineering leadership and industry-oriented innovation so as to make the selected students take the first chance.

From the joint faculty build of engineering leading talent plan in both school and enterprise, this article proposes the training plans of elite engineering leaders who take engineering planning and practical ability as the integrated traction after the students enter the enterprise, implements the joint guidance and flexibility management, and gives the quality assurance mechanism of training links based on the examination.

\section{Faculty Build by School-Enterprise Cooperation}

Leading talent training expert group should be established, by which all the work will be guided. The expert group is composed of professional teachers in the school and top-level teachers in the enterprise. In addition, because school can learn about more training situation after students enter the enterprises, full-time teachers are needed to be trained to meet the enterprise training.

\section{Professional Teachers Participate in Actual Project in Enterprise}

It is planned to send teachers to participate in various engineering leading training activities of enterprises and urge the teachers to complete the training contents of the leading courses to train more professional leading teachers. In order to further meet the requirements of the leading talent teaching, college will send young teachers every year to participate in enterprises for a period of time. In addition to directing the intern's graduation project, they also need to participate in the real project management in enterprise. In the teaching work after this, the practical experience learned in the enterprise should be applied to the teaching activities of the course.

\section{Establish Teacher Training Base in Enterprise}

On the basis of the existing student internship base, the college will optimize part of the internship base as a teacher training base, and will annually send young teachers to the enterprises for internship and training regularly and quantitatively. Through the past experience of leading students to practice internships in enterprises, we think that educators should consciously do what they ask others to do, which they should do first, just as what general secretary Xi Jinping pointed out, "college teachers should insist that educators first receive education." After the experience of enterprise, the teachers, especially the young teachers who directly enter school after graduation, will be more targeted in teaching and more emphasis on industry practice in scientific research.

\section{Based on Production Internship and Graduation Design, Develop Professional Teachers' Leading Experience}

By guiding the graduation design of the students who intern in enterprises every year, professional teachers will be improved in industrialization level, and will be cultivated engineering leading experience. The way that school professional teachers enter enterprise is essential to the teachers who lack the experience of working in the business. It not only directly inspires teachers thinking about the target of teaching and research work, but also promotes teachers to improve their own business ability. Although engineering leading talents training 
mainly to train outstanding students, however, professional teachers are also required to participate in the practice of enterprises in order to better guide and manage the students who follow the program.

\section{Executives or Teams to Guide}

After entering the enterprises, the students will be integrated into the project planning, management, research and development. With the business as the link, students will be directed guided by engineering and management staff of executives, form an enterprise mentor guidance pattern. The selected high-end industrial enterprises represent the development trend of the industry, with significant international characteristics and distinctive domestic characteristics, providing students with practical environment and platform directly facing the industry and creating opportunities to enhance engineering innovation and leadership that complements the education in school. There are obvious differences between the enterprise environment and campus environment. Enterprise provides a direct application of engineering practice and an important opportunity to participate in business management. Such occasions and opportunities have created the most suitable environment for the growth of engineering leaders. It is an important part in this project.

This program requires students to participate in the development of at least one real project of the enterprise and accomplish the research and development tasks arranged by the enterprise mentor. In this process, students are directly involved in the development and practice under the direct guidance of the business mentor, they can interact with the business mentor on planning, issues, techniques, methods, and so on. Obviously, this "direct" effect can give full play to the role of business mentor, making communication between teachers and students in the most efficient way. Enterprise mentors are usually staffed by senior executives who are chosen from senior managers and senior technical staff. Their mentality, decision-making process and ability, engineering planning and $\mathrm{R} \& \mathrm{D}$ skills, business management and operation process directly affect students and unconsciously influence the students' thinking. These comprehensive effects have a tremendous impact on students.

\section{Joint Guidance and Flexibility Management}

School professional teachers will participate in the enterprise-based joint training. The role of teachers tends to guide and grasp some certain aspects, while enterprise mentors tend to engineering management, development capabilities and engineering leadership.

As mentioned above, the senior staff will be the mentor to direct the students who enter the enterprise. Besides the engineering planning and practice, students also can participate in the process of business management. In the guidance and management of the integration of two aspects, students take engineering practice as the main way, which is completely different from the school education, so flexible management should be adopted. Obviously, this management should not only bring the characteristics of the company's staff management, but also take the characteristics of students into account to implement targeted guidance. On the other hand, after the student enters the enterprise, the school teacher also needs to jointly guide with the enterprise to carry out the coordinated education. School teachers not only should manage the students who enter the enterprise in the important time nodes, but also when the participate in the enterprise project development and business operation. They should even communicate with the students in time in thought, cooperate closely with enterprise mentors, and implement the engineering leading talents program together. 


\section{Elite Engineering Leading Talents Development Comprehensively Dragged by Project Planning, Practical Ability and Leadership}

On the basis of the achievements and the experience through cooperation with enterprises in talent training in the early stage, we have initially figured out the combination of school education and enterprise internship education to provide a new model of talent training led by engineering practice and management, and initially mastered the new education mechanism of combination of the class learning and engineering practice.

After the selected students enter the enterprises, they mainly accept the industrial education given by enterprises with engineering projects as the core. Enterprise senior leaders will be the mentors to guide from engineering development and enterprise management. The goal is to train the engineering innovation and leadership of elite students.

In order ensure students' internship in enterprise can achieve the expected goals of this project, we propose that the joint school-enterprise training should be conducted from the following three aspects: participate in the planning and development of the real project of the enterprise; assist supervisor to manage affairs and participate in the leadership and management; on the basis of the internship, finish the graduation design combining with the real enterprise project and write the dissertation. In these three aspects of the implementation process, students will be trained individually and managed flexibly, and the specific management of business education environment cannot be replaced by the rigid requirements. Figure 1 shows the training measures after students enter the enterprises.

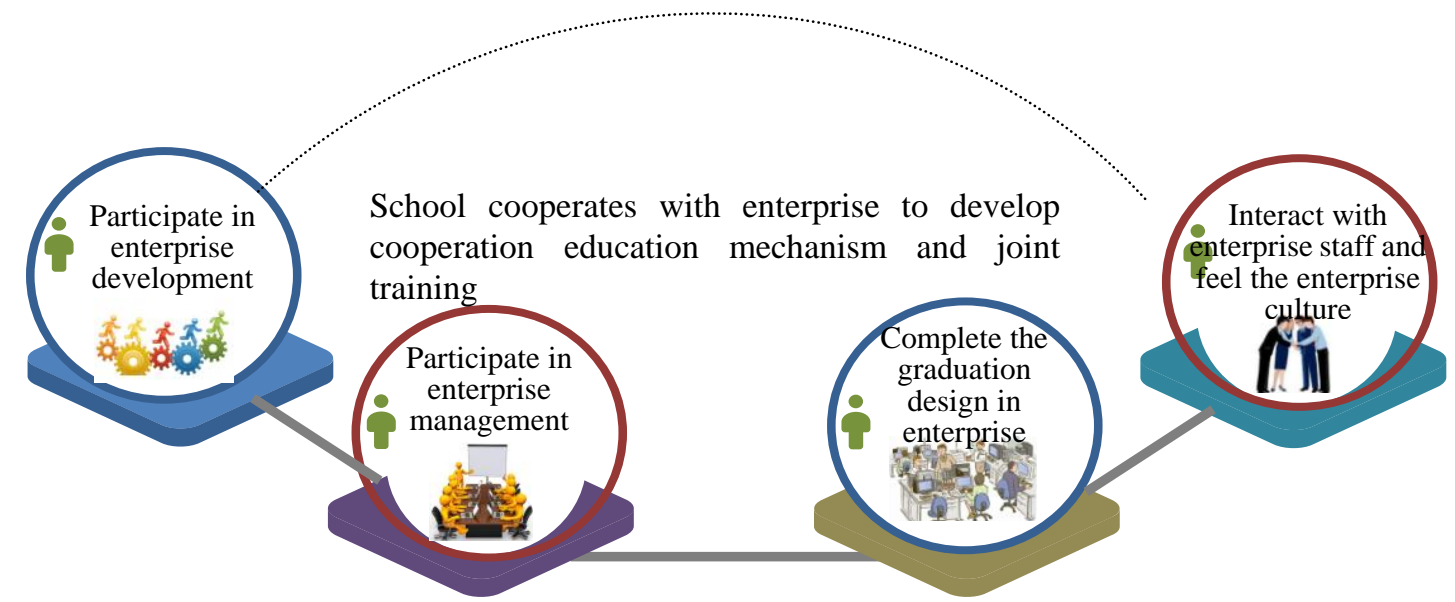

Figure 1 Elite engineering leading talent training measures

\section{Participate in the Real Project Planning and Development}

In this aspect, the engineering leading talent program focuses on the planning capacity training of engineering project and the subsequent research and development capabilities. Therefore, after entering the enterprise, the students should participate in the development of the real project of the enterprise under the arrangement of the enterprise mentor. In other words, students have to adjust the student mentality to employee mentality, which is the only way to truly feel development pace, and thus gradually improve the engineering innovation.

Combined with the scientific research experience of students in college laboratories, we will send different students to enter different enterprises and engage in no more than two following 
areas of research and development project, including enterprise and service intelligence computing, information security, Internet of things and embedded systems, bioinformatics computing, web analytics, visual computing and machine intelligence, parallel computing, big data management and intelligent multimedia.

This pertinence will greatly reduce students' strangeness or even fear of the engineering project after they enter enterprises, which will be more conducive to students to adapt quickly to the new environment.

After students enter the project, the business mentor will ask them to participate in the project planning, research and management, that is to engage in a certain amount of specific development work. At the same time, students should also participate in the management of some certain aspects of the work. With such continuous improvement, we can cultivate innovative awareness and ability in engineering and cultivate project management skills and leadership.

\section{Assist Supervisor in Management, Participate in the Leading Process}

Engineering leading talent training should also focus on training ability of organization and leadership. In this regard, under the guidance of the business mentor, students are integrated into the top management team of the enterprise and participate in decision-making in terms of project planning and management.

In the interaction with executives, students can always feel their perspicacity, organization ability, communication skill, and sense of responsibility. In the formation and implementation of management and decision-making, students can truly learn the organization and management of the enterprise and realize the project promotion strategy and other arrangements, so as to enhance the leading awareness and target to exercise leadership.

The important guideline of engineering leading talent training is the combination of engineering project innovation, core of which is professional knowledge, and management-core leadership. In the practice, thinking and transformation of facing the high-end industries, students are gradually moving toward the goal of engineering leading talents with top-notch innovation capability.

\section{Finish the Graduation Design Combined with Actual Enterprise Project}

The students who enter the engineering leading talent training program need to complete the graduation project in the enterprises they are working in. The title they make should come from the real project of the enterprise. The graduation design content (taking the factors such as confidentiality into account) can be derived from the engineering case and moderately condense or raise.

In this stage, students will be guided by the enterprise mentors, abstract the important innovation elements in graduation design content, and at the same time make the graduation design content more reflect the engineering and project characteristics to avoid the problems exposed in school graduation design.

\section{Give Full Play to the Coordinated Education Mechanism and Joint Training}

In order to ensure the training quality of students, college will regularly send teachers to work in the enterprise, not only participate in the management of real engineering project and accept training, but also mainly manage the students who enter the enterprise to get engineering leading talent training. They will communicate with enterprise mentors about the training 
situation and effectively solve the existing problems. College teachers should attend all the key points, including sending students to enter into enterprise, discussing the integration of students into engineering research and development and enterprise management, engineering project implementation, graduation project proposal, middle term inspection and other cases, so that the school-enterprise cooperating management can be brought and ensure the effective implementation of the joint education system.

Therefore, enterprise internship base is not only the place for students to improve engineering leadership, but also for both school and enterprise to manage and educate students. To this end, we will formulate the relevant institution and rules for school-enterprise cooperating training to make talent training more standardized.

\section{Quality Assurance Mechanism of Training Based on Examination}

In order to achieve the predetermined goal, according to the training process of the project, important parts of school education and enterprise education should be well controlled , and establish the appropriate assessment and quality assurance mechanism.

(1) Before the spring semester of junior, in accordance with different professional training programs, students must complete the relevant courses to lay the foundation for professional knowledge, skills and literacy. At the same time, they need to participate in annual innovation programs or science and technology competitions and other activities, lay the basic practical ability and innovation, in order to make the necessary preparations for shaping the engineering leadership. These contents should be credited into the training effectiveness assessment system from the course credit and innovation practice evaluation.

(2) In the spring semester of junior, students have to complete the following tasks:

(1) Student selection: Students volunteered to fill in the application form, and participate in the college written and interview. Written examination is based on professional knowledge, logical thinking and management ability assessment. Interview is based on the overall ability that various research project and scientific innovation competition need. Finally, we will admit the best students according to the comprehensive results.

(2) Choose the tutor: The two-way choosing principle is the basis for every admitted student to determine the school and enterprise tutors. Students can choose school teacher based on their own research project and scientific competition experience among all the teachers in college research center. While choose enterprise teacher, students also have to consider from their own research project and scientific competition experience, and choose from the enterprise list offered by college and the enterprises that the school tutor can contact. According to the students' interests and strengths, the school instructors guide the students in the follow-up field and the direction of the course selection, determine the internship training direction and specific internship tasks, give objective assessment to learning and practical work in each stage, and credit in innovation credits, practice credits and record in the training effectiveness assessment system.

(3)Finish other professional courses of this semester, continue to enrich their professional knowledge and improve their professional skills. At the same time, complete the school's leading talent management courses to enable students to initially have the necessary management knowledge into the enterprise and engineering leadership requirements. These learning results are credited to the course credit and training effectiveness assessment system. 
(3) In junior summer semester, according to the arrangement of tutors inside and outside the school, students have to intern in the enterprise for three months to initially establish a professional and technical ability to adapt to the business environment, and adjust mentality appropriately.

(4) In senior fall semester, finish optional courses, finish school graduation design, management and leadership training. Assessment method is course examination, oral defense, and students have to be assessed by professional course teachers and training teachers.

(5) In senior spring semester, students have to complete a development task in the enterprise, so that they can really integrate into enterprise engineering project practice and have full contact with enterprise staff, especially mentors., Students write the graduation paper based on real engineering project. After concluding, students participate in the oral debate organized by college. While attending the real project of the enterprise, they should also enter an enterprise management project as the assistant of project group executives, and participate in product or system research and development, project planning and other sectors. Enterprise mentors will give assessment, and the results will be counted into graduation design result. The enterprise mentor will give student their final evaluation according to their performance and achievement in the engineering project practice, give assessment of the role they play in the process of enterprise management project and it will be recorded into the development effectiveness assessment system.

During the entire process of implementation, when student can't reach the predict target in any course or learning part, or they can't meet the basic requirements in any practice effectiveness assessment, the following process will be terminated. Through the assessment of course learning and practice inside and outside school, an effective assurance mechanism will be built.

In the concrete implementation, the plan should adopt the fast iterative method, which is often used in the computer industry development, practice first, then summarize, then practice and then summarize. In each progress year of the project, the quality assurance mechanism will be adjusted based on the conclusion, and will be implemented in following process to ensure that a practical project quality assurance mechanism can be established.

\section{Conclusion}

Engineering Leading Talent training program should give full play to the comprehensive advantages of coordinated education by school and industry, and construct a cross-joint education system that integrates school teachers and enterprise mentors. High-end engineering leading talents with top-notch innovation and engineering leadership can be cultivated from school courses and research projects, real engineering practice and participation in business management. From the perspective of faculty build and cooperated education, this paper presents the school-enterprise faculty build plan, which is necessary in engineering leading talent training program, proposes the measures for students to improve engineering innovation and leadership after they enter enterprise, and give the training quality assurance mechanism based on assessment. Engineering leading talent training program faces the needs of high-end industry development, open up a new path for the cultivation of engineering leading talents in colleges and universities, which will surely bring more useful references to the school-enterprise cooperated development and education. 


\section{Acknowledgement}

In this paper, the research was sponsored by the 2016 Research and Practice on Engineering Leading Talent Training Mode for Engineering Top-notch Talents of Shandong Province Undergraduate Teaching Reform Research Project (B2016M016), the 2017 project of collaborative education for production-learning cooperation of the Ministry of Education, "Laboratory of IoT Labs focusing on cultivating complex engineering problem-solving capabilities", the 2016 Shandong Province Graduate Education Innovation Project Special Project "Multidimensional Education Quality for Professional Degree Graduate Students Evaluation System (SDYZ1603) ", and Research Project "Research and Practice of Internet of Things Talents Training Model" of Harbin Institute of Technology at Weihai (BK201602).

\section{References}

[1] Lin J, Xu Z D. International Engineering Leadership Education and Its Enlightenment to China (I)[J]. Higher Engineering Education Research, 2014(3): 7-17.

[2] Li D, Yin S J. Focus on Engineering Leadership and Train IT Engineering Leading Talents[J]. Computer education, 2015(15): 2-5.

[3] Lei Q, Gong X. An Analysis of the Features of the Project-based Talents Training Programs for Undergraduate Stage - A Case Study of Gordon-MIT Project Leadership Program $[\mathrm{J}]$. Journal of Beijing University of Aeronautics and Astronautics (Social Sciences Edition), 2010, 23(1): 108-113.

[4] Lei H, Crawley E. Develop Engineering Leadership to Lead the Development of the World - MIT Gordon Engineering Leadership Program Overview[J]. Tsinghua University Education Research, 2010, 31(1): 77-83.

[5] Ye W W, Ye M. Research on Engineering Leadership Factors[J]. Higher Engineering Education Research, 2011(5): 92-95.

[6] Lin J. Excellent engineer leadership training[J]. Higher Engineering Education Research, 2012(4): 1-14.

[7] Zhang D L. Sino-French cooperation in cultivating leading talents in the field of engineering $[\mathrm{J}]$. International talent communication, 2010(5): 62-62.

[8] http://www.huaue.com/unews2014/2016111283127.htm.

[9] Li Z Q. Exploration and Analysis of Undergraduates' Engineering Leadership Training[J]. Continuing education research, 2013(8): 122-124.

[10]Cui J, Wang X. Develop Engineering Leader: Engineering Leadership Education at MIT[J]. Higher science education, 2010(6): 30-35.

[11]Zhou J, Guo A H. Engineering Leadership Training in Higher Education[J]. Computer education, 2013(5): 106-110.

[12]Liang G M. A Comparative Study of Engineering Leadership Training in USA and Russia[D]. Harbin Institute of Technology, 2013. 